\title{
On the resistance of rare earth oxide-doped YSZ to high temperature volcanic ash attack
}

\author{
J. Xia ${ }^{\mathrm{a}, \mathrm{b}}$, L. Yang ${ }^{\mathrm{a}, \mathrm{b}, *}$, R.T. Wu ${ }^{\text {b,c }}$, Y.C. Zhou ${ }^{\mathrm{a}, \mathrm{b}, *}$, L. Zhang ${ }^{\mathrm{d}}$, B.B. Yin ${ }^{\mathrm{a}, \mathrm{b}}$, Y.G. Wei ${ }^{\mathrm{e}}$ \\ a Key Laboratory of Key Film Materials \& Application for Equipment (Hunan Province), School of Materials Science and Engineering, Xiangtan University, Xiangtan, Hunan 411105, China

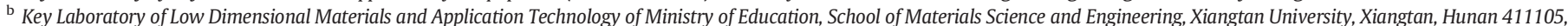 \\ China \\ ${ }^{c}$ National Institute for Materials Science, 1-1 Namiki, Tsukuba, Ibaraki 305-0044, Japan \\ d College of Materials Science and Engineering, Chongqing University, Shazhenghie 174, Chongqing, 400045, China \\ e LNM, Institute of Mechanics, Chinese Academy of Sciences, Beijing 100190, China
}

\section{A R T I C L E I N F O}

\section{Article history:}

Received 8 June 2016

Revised 14 September 2016

Accepted in revised form 16 September 2016

Available online 17 September 2016

\section{Keywords:}

Thermal barrier coatings

Rare earth-doped YSZ

Volcanic ash

CMAS

\begin{abstract}
A B S T R A C T
Thermal barrier coatings (TBCs), such as 7-8 wt.\% yttria stabilized zirconia (YSZ), are widely used to reduce the temperature of coated materials. However, when a turbine operates in a harsh environment, for example a volcanic ash attack, sand and ash particles ingested by the engine could be deposited on the TBC surfaces as molten calcium-magnesium-alumino-silicate (CMAS). CMAS melts and penetrates into TBCs at high temperatures, which causes a loss of strain tolerance and results in the premature failure of the top coat. It is recognized that the formation of CMAS is inevitable due to exposing the turbine to sand and ash; therefore, CMAS mitigation solutions are among the top challenges for materials scientists. To some extent, CMAS is the biggest weakness of the traditional 7-8YSZ TBC material. The thermochemical interactions between YSZ and real volcanic ash are investigated in this paper as a means to alleviate the volcanic ash attack by understanding the underlying mechanisms. 7YSZ, 0.5Gd-8YSZ and 3Er-7YSZ powders and free-standing plates were prepared, respectively. The effect of the volcanic ash on the three different samples was investigated using an X-ray diffraction, scanning electron microscopy, a scanning transmission electron microscopy, and a differential scanning calorimetry. The phase transformations and reaction of TBCs materials subjected to a volcanic ash attack were examined and the volcanic ash degradation and mitigation mechanisms were discussed. It was found that rare earth-doped YSZ samples suffered less damage from the volcanic ash attack than the standard 7YSZ. The results demonstrate that rare earth-doped YSZ may be effectively utilized to mitigate a volcanic ash attack.
\end{abstract}

(C) 2016 Published by Elsevier B.V.

\section{Introduction}

The thrust and fuel efficiency of jet engines are directly related to the temperature of the gas entering the turbine section [1]. The development of civilian engine technology has led to an increasing interest in introducing materials capable of operating at higher temperatures to increase engine efficiency. This demand has been partially fulfilled by advancing superalloy technology. Jet engines have benefited from decades of development of nickel-based superalloys [2], which have enabled a steady increase in engine operating temperatures and led to improved performance and efficiency. However, restricted by the melting temperatures of superalloys, operating temperatures are now reaching their

\footnotetext{
* Corresponding authors at: Key Laboratory of Key Film Materials \& Application for Equipment (Hunan Province), School of Materials Science and Engineering, Xiangtan University, Xiangtan, Hunan 411105, China.

E-mail addresses: lyang@xtu.edu.cn (L. Yang), zhouyc@xtu.edu.cn (Y.C. Zhou).
}

limit. Thermal barrier coatings (TBCs) are used to meet the demand and protect turbine engines from thermally-induced damage. TBCs are a complex system of coatings with many different functions [3]. The typical structure of TBCs consists of four layers, including a ceramic top coat, thermally-grown oxide, a bonding coat, and a superalloy substrate. 7-8 wt.\% yttria stabilized zirconia (7-8YSZ) has been used as a top coat material for decades [2]. This material has gained popularity because it has an extremely low thermal conductivity, high toughness value, and a relatively high thermal expansion coefficient which better matches a metallic substrate. The further enhancement of energy efficiency, the thrust-to-weight ratio and durability of gas turbine engines depend on the further improvement of TBCs [4].

The TBCs system could fail in many different ways [5], being exposed to extreme stress and a thermal environment. These failures are likely to occur at the thermally-grown oxide interface with the bond coat or the top coat. Damage can also come from the stress induced by a thermal expansion mismatch between the underlying substrate and the ceramic 
top coat. Damage from the ingestion of foreign objects also threatens the integrity of the ceramic top coat. Thus, it is paramount to understand these various degradation mechanisms and their effect on the overall lifetime of TBCs. However, with increasing operating temperatures, TBCs are facing new challenges, such as when the turbine operates in a severe environment, sand and ash particles ingested by the engine could be deposited on the TBCs surface as molten calcium-magnesiumalumino-silicate (CMAS) [6] and result in the degradation of the ceramic coating.

In the early 1990s, it was observed that engine failure occurred near volcanic dust clouds or in desert areas that had large amounts of airborne sand or ash. Engine failure was identified as the result of crusty deposits that formed on the inside of the engine [7,8]. CMAS melts and penetrates into the TBCs at high temperatures, causing the loss of strain tolerance and spallation failure of the coatings. The molten CMAS can chemically dissolve the coating material, which is usually followed by the precipitation of a modified oxide. Yttria diffuses out from the top coat into the molten CMAS resulting in a tetragonal to the monoclinic phase transformation in the YSZ [9]. Since all prospective TBCs have to be porous to render their strain tolerance and most silicate deposits melt at around $1200{ }^{\circ} \mathrm{C}$, any increase in the operating temperature to enhance the turbine efficiency would require finding solutions to the CMAS problem [6]. Krämer et al. found that the wetting of CMAS on TBCs can start within seconds at $1300{ }^{\circ} \mathrm{C}$ [9]; nevertheless, no oxide layer was detected at the bonding interface in such a short time [10]. Therefore, CMAS wetting and penetration can be expected to happen within a short time at temperatures above or in the CMAS melting range. CMAS mitigation solutions are in need of critical development and this will continue to challenge materials scientists. To some extent, CMAS is the biggest weakness of TBCs [11]. Two of the typical numerous CMAS mitigation strategies for the YSZ top coat that have been proposed in the literature entail i) the deposition of a protective coating on the surface of the top coat, or the incorporation of sacrificial materials, such as depositing a dense, non-cracked and non-porous ceramic, or metal impermeable or non-wetting outer layer to inhabit the infiltration of molten CMAS [12]; ii) the replacement of 7-8YSZ by rare-earth zirconates or low thermal conductivity rare-earth oxides [6,13]. Rare earth zirconates generally offer lower thermal conductivity and enhanced sintering resistance relative to $\mathrm{t}^{\prime}$-YSZ, although there are some concerns about their lower level of toughness [6,14]. However, most rare earth oxides are polymorphic at elevated temperatures and this phase transformation affects their ability to resist a thermal shock to some extent [15]. When engineering TBCs, the materials need to have a set of properties to form a useful top coat, i.e. low thermal conductivity, phased stability through a high temperature range, chemical stability, and a coefficient of thermal expansion match. However, satisfying all of these requirements can be conflicting; therefore, it is essential to understand the complex thermochemical reactions between CMAS and YSZ in order to develop alternative coating compositions, designed to mitigate CMAS-induced degradation.

Its impact on air traffic can be well demonstrated by the eruption of Iceland's Eyjafjallajokull volcano in 2010, which caused thousands of flights to be canceled and resulted in a 1.7 billion dollar economic loss [16]. With 50-70 volcanic eruptions every year, volcanic ash is expected to impact more aero-engines in the future [17]. If the aircraft has traveled through the path of volcanic plumes, these particles will cause severe degradation to the components of the turbine engine. It is recognized that low level exposure to volcanic ash in the atmosphere is probably inevitable and volcanic ash damages engine components and can thus lead to engine failures [17]. The attack of degradation mechanisms on TBCs induced by molten VA is somewhat similar to that responsible for CMAS degradation. The exposure of aircraft engines to VA can have a significant impact on engine performance, flight safety and maintenance costs. However, it is clear that the long term effects of CMAS-type contaminants on the thermomechanical performance of TBCs is yet to be fully determined and it is crucial to understand these effects on the development of next generation TBCs to ensure that they can better resist a VA attack.

The focus of this paper is the interaction of 7YSZ and rare earth oxide-doped YSZ with volcanic ash. The phase transformations and chemical reaction of TBC materials subjected to a volcanic ash attack are examined, and the VA degradation and mitigation mechanisms are discussed. It is found that rare earth oxide-doped YSZ may be effective in mitigating a volcanic ash attack.

\section{Experimental procedure}

\subsection{Preparation of volcanic ash and TBCs materials}

The volcanic ash utilized in this study was obtained from the March 10th 2009 eruption of Sakurajima volcano, Kagoshima Prefecture, Japan. The ash was collected near the Furusato hot spring, approximately $5 \mathrm{~km}$ from the eruption center. The ash was ball milled and then screened using a 500-mesh sieve. A small amount of rare earth oxide-doped YSZ (3Er-7YSZ, 0.5Gd-8YSZ) and 7YSZ ceramic plates machined from the ingot were used to resemble the TBCs top coat. Both YSZ and rare earth oxide-doped YSZ materials were obtained from ingots used for EB-PVD coating and machined to plate-like structures. The three samples studied here and their composition are listed in Table 1.

\subsection{Heat treatment}

The interaction between the VA and ceramic materials was conducted by heat treatment performed in a box furnace. The VA was evenly placed on the surface of the ceramic plates with a loading concentration of about $20 \mathrm{mg} / \mathrm{cm}^{2}$ first, which was subsequently heat treated at $1250{ }^{\circ} \mathrm{C}$ for $5 \mathrm{~h}$, well above the measured melting temperature of VA. When the furnace reached $1250{ }^{\circ} \mathrm{C}$, the samples were inserted and held for $5 \mathrm{~h}$, followed by natural cooling to room temperature inside the furnace, which is preferable for minimizing the temperature ramp-up time. Meanwhile, the VA was also mixed with different ceramic powders with a weight ratio of $1: 1$, representative of the situation within TBCs pores or channels where the melt is surrounded by a large amount of ceramics. The mixture was then transferred to crucibles, which were placed in the furnace and treated under the same conditions.

\subsection{Characterization}

Particle size distributions of VA were obtained using a particle-size analyzer (Mastersizer 2000, Malvern Instruments, UK). In order to study the high temperature interactions between the VA and TBCs, the composition of the VA was measured by X-ray fluorescence (XRF) and its crystallinity was measured using X-ray diffraction (XRD).

Differential scanning calorimetry (DSC) was used to study the onset of the phase transformation, melting and reactions between the VA and as-prepared ceramics. The experiment was undertaken using a Netzsch 404F3 instrument and Pt-Rh crucibles with pierced lids for enhanced detection sensitivity. Pt-Rh crucibles were utilized instead of alumina types to ensure the minimum reaction between the crucible and the samples. The crucibles were rested on thin $\mathrm{Al}_{2} \mathrm{O}_{3}$ washers to prevent adhesion to the instrument stage at high temperatures. With respect to the temperature profile, the samples were heated from room temperature to $1400{ }^{\circ} \mathrm{C}$ at a heating rate of $10{ }^{\circ} \mathrm{C}$ per minute, followed by a 10 -

Table 1

Compositions of the samples studied.

\begin{tabular}{llll}
\hline Sample ID & $7 \mathrm{YSZ}$ & $3 \mathrm{Er}-7 \mathrm{YSZ}$ & $0.5 \mathrm{Gd}-8 \mathrm{YSZ}$ \\
\hline $\begin{array}{c}\text { Composition } \\
\text { (wt.\%) }\end{array}$ & $7 \% \mathrm{Y}_{2} \mathrm{O}_{3}-93 \% \mathrm{ZrO}_{2}$ & $3 \% \mathrm{Er}_{2} \mathrm{O}_{3}-97 \%$ (7YSZ) & $0.5 \% \mathrm{Gd}_{2} \mathrm{O}_{3}-99.5 \%(8 \mathrm{YSZ})$ \\
\hline
\end{tabular}




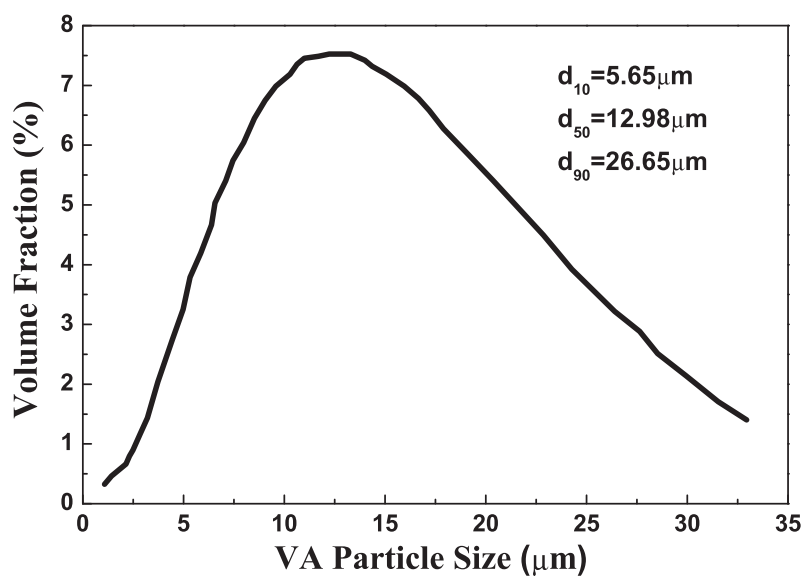

Fig. 1. Particle size distributions of sieved VA powders.

minute hold at the peak temperature, before being cooled down to room temperature at a controlled rate of $10{ }^{\circ} \mathrm{C}$ per minute between $1400{ }^{\circ} \mathrm{C}$ and $200{ }^{\circ} \mathrm{C}$. The atmosphere in the chamber was kept under argon (Ar) gas throughout the entire analysis. The volcanic ash alone, and VA-ceramics mixtures were analyzed and $30 \mathrm{mg}$ of the sample was used for each measurement, while the mixed powder samples were prepared in a 1:1 weight ratio (i.e. $15 \mathrm{mg}$ each).

Plate samples obtained after the heat-treatment in the box furnace were mounted vertically in epoxy so that a cross-sectional image of the ceramic plates could be obtained. The cross-section of samples were polished using standard metallographic techniques. The depth of penetration was determined using a scanning electron microscopy (JSM-7500F FE-SEM) equipped with an energy-dispersive X-ray spectroscopy (EDX) detector. The porosity (void fraction) of each sample was observed and calculated using the "Digital Micrographic" program. Porosity measurements of the samples were performed on 5 different areas and calculated as the average of these 5 values. The porosity (void fraction) values of 7YSZ, 3Er-7YSZ and $0.5 \mathrm{Gd}-8 \mathrm{YSZ}$ were $12.75 \% \pm 0.53 \%, 15.31 \% \pm 0.48 \%$ and $14.63 \% \pm 0.62 \%$, respectively.

The phased composition of TBC ceramics powders and 1:1 (by weight) mixtures of the VA and ceramic powders after heat-treatment at $1250{ }^{\circ} \mathrm{C}$ for $5 \mathrm{~h}$ were analyzed using XRD with $\mathrm{Cu}-\mathrm{K} \alpha(\lambda=$ $0.15406 \mathrm{~nm}$ ) radiation at a scan rate of $3.5^{\circ} / \mathrm{min}$. The VA-corroded powder samples were examined in order to further reveal the feature of the VA-induced phase transformation and chemical reaction in the asprepared ceramic materials, using a scanning transmission electron microscopy (STEM) equipped with an energy dispersive spectroscopy (EDS) detector.

\section{Results}

\subsection{Characterization of volcanic ash}

The particle size distributions of sieved VA powder are shown in Fig. 1. The as-prepared VA powder shows a continuous grain size distribution from $1 \mu \mathrm{m}$ to $35 \mu \mathrm{m}$, and d10, d50, d90 (i.e. $10 \%, 50 \%$ and $90 \%$ ) values of approximately $5.65 \mu \mathrm{m}, 12.98 \mu \mathrm{m}, 26.65 \mu \mathrm{m}$ respectively. The compositions of the volcanic ash which was analyzed with XRF are given in Table 2 [16]. Ca, Mg, $\mathrm{Al}, \mathrm{Si}, \mathrm{Fe}, \mathrm{K}$ and Ti were found in the volcanic ash, similar to the volcanic ash compositions in Iceland's

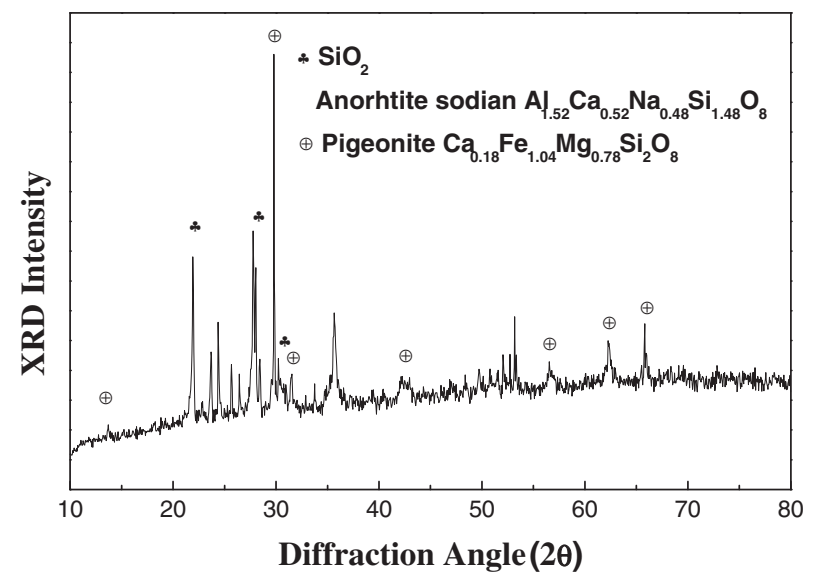

Fig. 2. XRD pattern of VA.

Eyjafjallajokull reported by Mechnich et al. [18]. VA has a composition similar to CMAS, but with a lower melting temperature. Fig. 2 shows the XRD analytical results of the volcanic ash, which indicated the existence of crystalline peaks. The majority of these peaks were identified as $\mathrm{SiO}_{2}$, anorthite sodian $\left(\mathrm{Al}_{1.52} \mathrm{Ca}_{0.52} \mathrm{Na}_{0.48} \mathrm{Si}_{2.48} \mathrm{O}_{8}\right)$ and pigeonite $\left(\mathrm{Fe}_{1.04} \mathrm{Mg}_{0.78} \mathrm{Ca}_{0.18} \mathrm{Si}_{2} \mathrm{O}_{6}\right)$. However, the $\mathrm{K}$ and Ti phases were not detected, possibly due to their low concentration and the complexity of the XRD pattern.

A DSC analysis was performed to determine the onset melting temperatures of the volcanic ash and the VA mixed with the as-prepared ceramic powders as shown in Fig. 3. In Fig. 3(a), a change in the slope is observed at $1062.7^{\circ} \mathrm{C}$ representing the onset of melting, while peak melting occurs at around $1168.2^{\circ} \mathrm{C}$. When the temperature is higher than $1062.7^{\circ} \mathrm{C}$, volcanic ash is expected to melt and penetrate the coating, which threatens the structural integrity of TBCs. It should be noted that the melting range mentioned above depends on the chemistry of the volcanic ash, which tends to vary geographically.

The relevant transformation temperatures taken from DSC scans are summarized in Table 3. Compared to the VA, the temperatures of the melting peak in the VA-7YSZ sample shifted to lower values, with the onset depressed by $14.1^{\circ} \mathrm{C}$ and the peak by $22.1^{\circ} \mathrm{C}$. However, the melting temperature increased slightly in the case of the rare earth-doped samples. The melting ranges decreased slightly relative to the VA.

\subsection{Penetration of volcanic ash in 7YSZ and rare earth-doped YSZ plates}

The cross-sectional micro-graphs and EDX mapping of the asprepared ceramic samples with volcanic ash deposits after heat treatment at $1250^{\circ} \mathrm{C}$ for $5 \mathrm{~h}$ are shown in Fig. $4 . \mathrm{Zr}, \mathrm{Si}, \mathrm{Y}, \mathrm{Gd}$, and Er were detected in the EDX mapping, where $\mathrm{Zr}$ and Si were originally only present in the as-prepared ceramics and VA, respectively. The presence and distribution of Si through the coating cross-section suggest that the VA had penetrated the ceramic plates. The comparison of the thickness of the interactive layers of the samples during heat treatment is depicted in Table 4 . The interactive layer was measured by taking the average of the penetration depth from areas where VA deposition was clearly visible. After the heat treatment, the penetration depth of the 7YSZ sample was about $322.5 \pm 26.6 \mu \mathrm{m}$. In contrast, the volcanic ash interactive region in the samples of 3Er-7YSZ and 0.5Gd-8YSZ only approached a thickness of $86.0 \pm 35.0 \mu \mathrm{m}$ and $108.2 \pm 20.2 \mu \mathrm{m}$, respectively. The

Table 2

Composition of volcanic ash measured by XRF (at.\%) [15].

\begin{tabular}{|c|c|c|c|c|c|c|c|c|c|c|c|c|}
\hline Element & $\mathrm{Si}$ & $\mathrm{Al}$ & $\mathrm{Fe}$ & $\mathrm{Ca}$ & $\mathrm{Mg}$ & K & $\mathrm{Ti}$ & $\mathrm{Na}$ & $\mathrm{Mn}$ & $\mathrm{P}$ & $\mathrm{Ta}$ & 0 \\
\hline Volcanic ash & 35.44 & 10.27 & 9.46 & 6.39 & 4.02 & 1.99 & 0.94 & 0.57 & 0.22 & 0.19 & 0.03 & Bal. \\
\hline
\end{tabular}



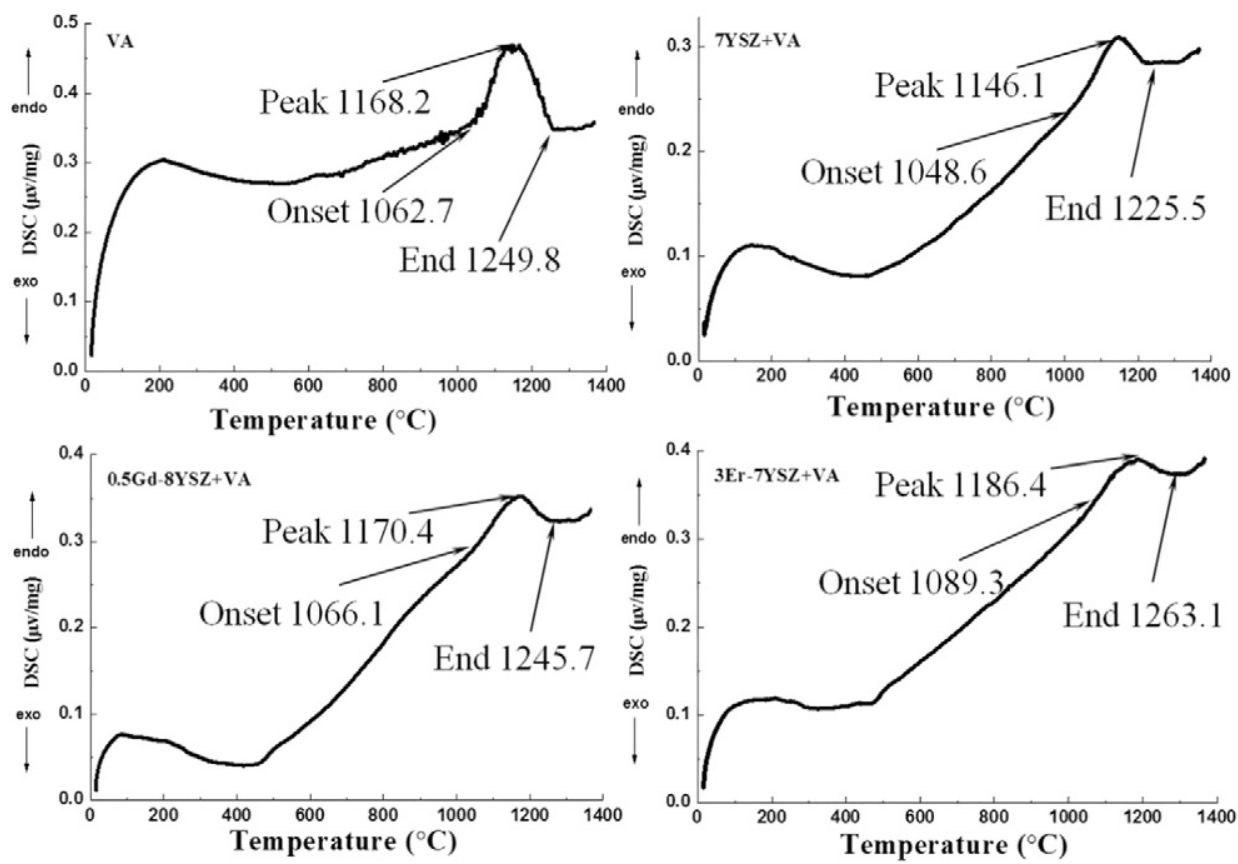

Fig. 3. DSC pattern of VA, VA mixed with 50\% 3Er-7YSZ, 50\% 0.5Gd-8YSZ and 50\% 7YSZ, respectively.

Table 3

A summary of relevant temperatures taken from DSC scans $\left({ }^{\circ} \mathrm{C}\right)$

\begin{tabular}{lllll}
\hline Sample ID & VA & 7YSZ & $0.5 G d-8 Y S Z$ & 3Er-7YSZ \\
\hline Onset & 1062.7 & 1048.6 & 1066.1 & 1089.3 \\
Peak & 1168.2 & 1146.1 & 1170.4 & 1186.4 \\
End & 1249.8 & 1225.5 & 1245.7 & 1263.1 \\
Melting range & 187.1 & 176.9 & 179.6 & 173.8 \\
\hline
\end{tabular}

SEM and EDX analysis results of the new ceramics showed that 3 wt.\% $\mathrm{Er}_{2} \mathrm{O}_{3}$ and $0.5 \mathrm{wt}$.\% $\mathrm{Gd}_{2} \mathrm{O}_{3}$ additions make $\mathrm{YSZ}$ more resistant to VA penetration than the standard 7YSZ. It could be seen that 7YSZ showed a relatively poor ability to combat volcanic ash penetration.

\subsection{Volcanic ash interaction with 7YSZ and rare earth-doped powders}

The X-ray diffraction patterns of the as-prepared ceramics are shown in Fig. 5(a). The 7YSZ is composed of non-transformable tetragonal $\left(\mathrm{t}^{\prime}\right)$ phase zirconia, which is the desirable $\mathrm{ZrO}_{2}$ phase for TBCs and is in agreement with the expected composition according to the $\mathrm{Y}_{2} \mathrm{O}_{3}$ $\mathrm{ZrO}_{2}$ phase diagram [19]. The XRD patterns of VA-loaded ceramic samples after heat treatment at $1250^{\circ} \mathrm{C}$ for $5 \mathrm{~h}$ are shown in Fig. 5(b). The XRD diffraction pattern contains the same $\mathrm{ZrSiO}_{4}$ and unreacted $\mathrm{t}^{\prime}-$ $\mathrm{ZrO}_{2}$ peaks in the heat treated samples of VA separately mixed with 0.5Gd-8YSZ and 3Er-7YSZ powders, only with different peak intensities. However, the rare earth phase was not detected possibly due to its low


Fig. 4. The cross-sectional micro-graphs and EDX mapping of (a) 7YSZ, (b) $0.5 \mathrm{Gd}-8 \mathrm{YSZ}$ and (c) $3 \mathrm{Er}-7 \mathrm{YSZ}$ samples with volcanic ash deposits after heat treatment at $1250{ }^{\circ} \mathrm{C}$ for $5 \mathrm{~h}$. 
Table 4

A summary of penetration depth results and melting temperatures for each sample.

\begin{tabular}{llll}
\hline Sample ID & Atomic ratio & Melting temperature $\left({ }^{\circ} \mathrm{C}\right)$ & Penetration depth $(\mu \mathrm{m})$ \\
\hline 7YSZ & 0.0822 & 1146.1 & $322.5 \pm 26.6$ \\
0.5Gd-8YSZ & 0.0988 & 1170.4 & $108.2 \pm 20.2$ \\
3Er-7YSZ & 0.1035 & 1186.4 & $86.0 \pm 35.0$ \\
\hline
\end{tabular}

concentration. The presence of unreacted $\mathrm{t}^{\prime}-\mathrm{ZrO}_{2}$ was also observed in the heat treated VA-7YSZ sample. Moreover, the presence of a considerable number of $\mathrm{ZrSiO}_{4}$ XRD peaks in the heated treated VA-7YSZ revealed significant thermochemical degradation by the VA. It should be noted that a significant phase transformation to a monoclinic zirconia $\left(\mathrm{m}-\mathrm{ZrO}_{2}\right)$ phase was only observed in the 7YSZ mixed with VA and peaks corresponding to crystalline VA were not detected among all the samples.

In order to examine the interaction of VA and the as-prepared ceramics in more detail, investigations by STEM and selected area electron diffraction (SAED) were carried out on VA-degraded ceramic samples prepared in powder form. STEM images are shown in Fig. 6, and the EDS mapping of the original 7YSZ powders in Fig. 6(a) and Fig. 6(b), (c), (d), and the SADP of the area A as marked in Fig. 6(a) is shown in Fig. 6(e). The primary crystalline phases in this region are made of $\mathrm{t}^{\prime}$ $\mathrm{ZrO}_{2}$, as can be seen from the EDS spectrum in Fig. 6(e). These observations are consistent with the XRD results in Fig. 5(a). The STEM was performed on the reactive products between the 7YSZ and VA powders after heat treatment at $1250{ }^{\circ} \mathrm{C}$ for $5 \mathrm{~h}$, as shown in Fig. 7 ; $\mathrm{ZrSiO}_{4}$ (Fig. 7(b) and (c)) and $\mathrm{m}-\mathrm{ZrO}_{2}$ (Fig. 7(d) and (e)) were present. These observations are also consistent with the XRD results in Fig. 5(b). Glass (Fig. 7(f) and (g)) was found in area C as marked in Fig. 6(a), which was the unreacted VA. The STEM images of 3Er-7YSZ/VA powders after heat treatment at $1250{ }^{\circ} \mathrm{C}$ for $5 \mathrm{~h}$ are shown in Fig. 8, the EDS maps in Fig. 8(b) to (f) and EDS spectra corresponding to area A, $\mathrm{B}$ and $\mathrm{C}$, respectively, in Fig. 8(g) to (i). However, the rare earth phases supposed to be present in the reactive products was not observed in the STEM, probably due to its low concentration.

\section{Discussion}

The detailed analyses of the reaction between the as-prepared ceramics and VA will be discussed in this section. Fig. 5(a) confirmed that the $\mathrm{t}^{\prime}-\mathrm{ZrO}_{2}$ was the major phase in the as-prepared ceramic
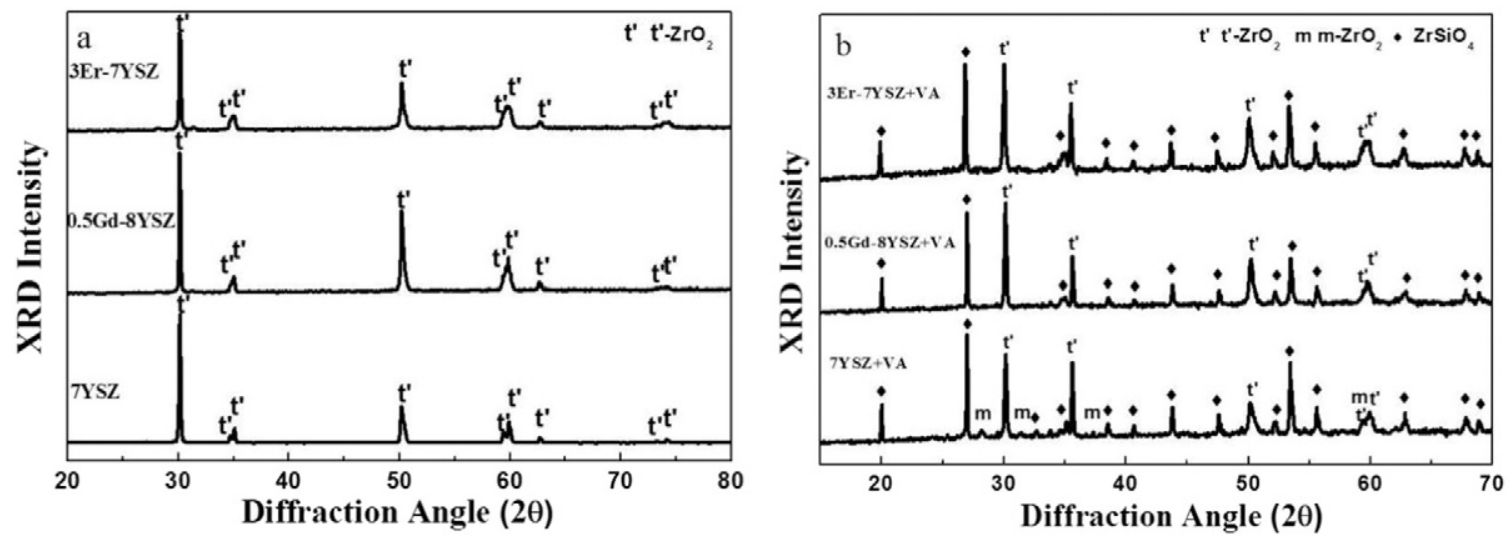

Fig. 5. XRD pattern of (a) as-prepared ceramics and (b) VA/as-prepared ceramics mixture after heat treatment at $1250{ }^{\circ} \mathrm{C}-5 \mathrm{~h}$.

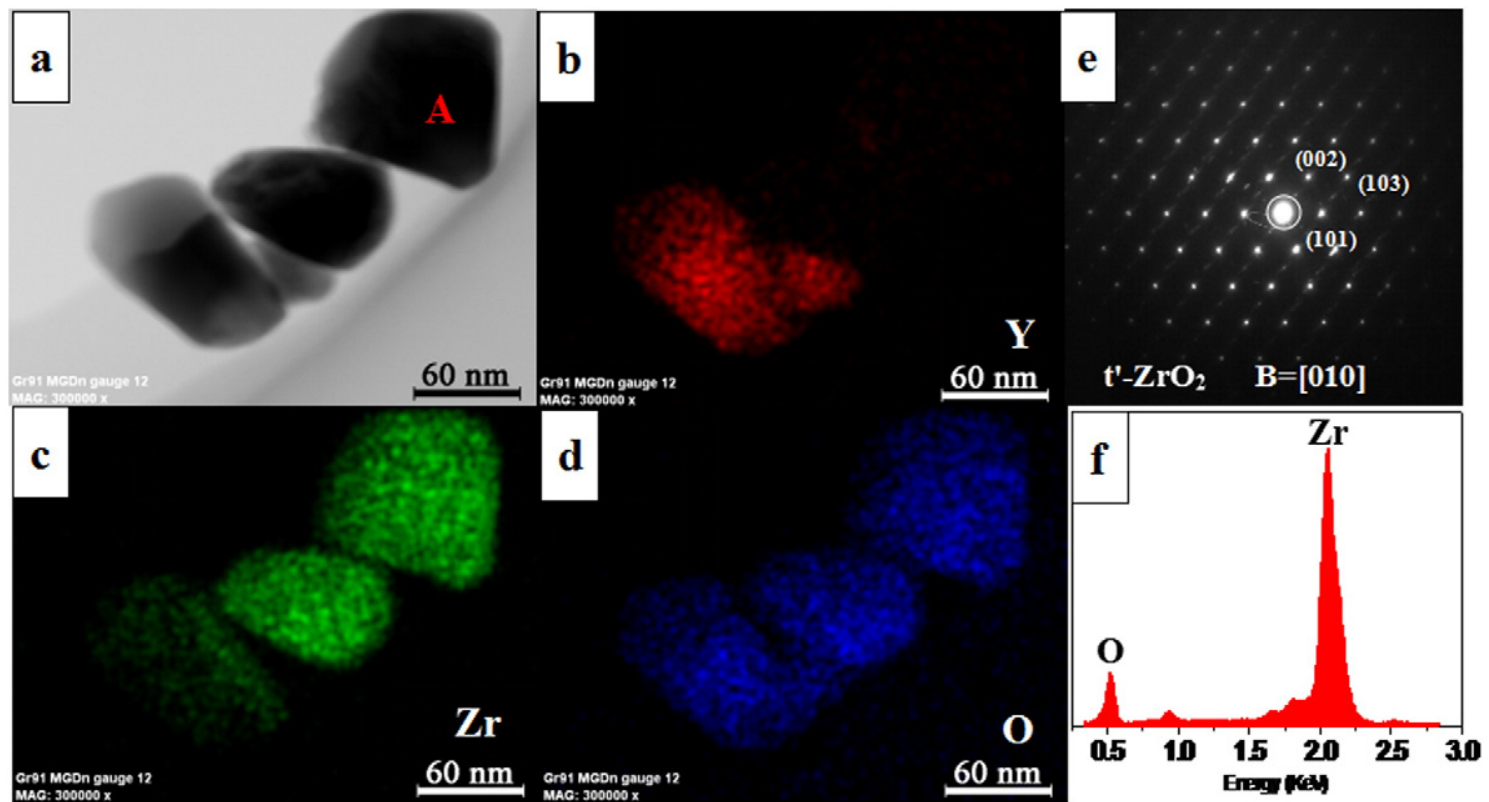

Fig. 6. (a) STEM images, (b) Y, (c) Zr and (d) O EDS map of the original 7YSZ powders, (e) SADP of area A and (f) EDS spectrum in area A. 


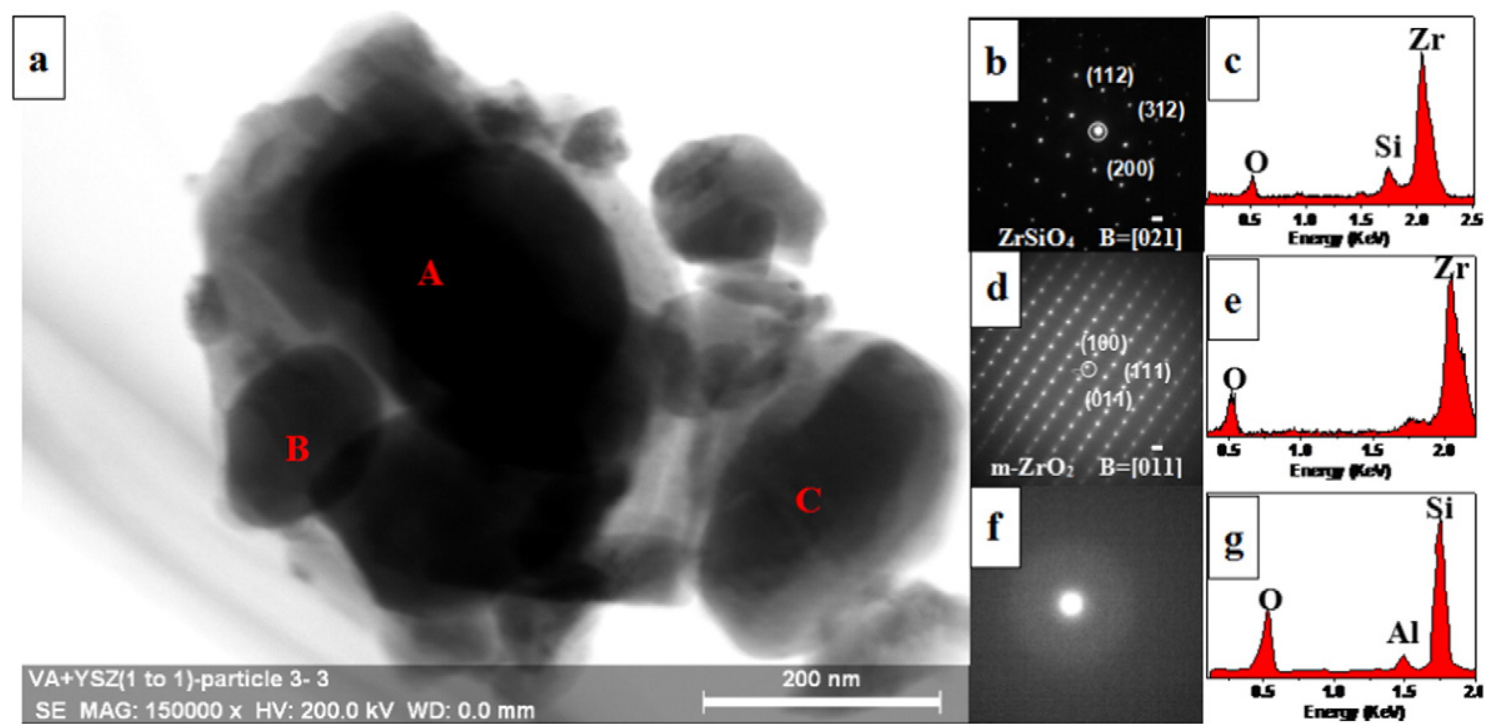

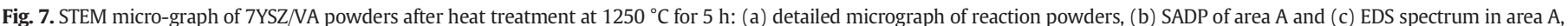
(d) SADP of area B and (e) EDS spectrum in area B, (f) SADP of area C and (g) EDS spectrum in area C.

powder. However, the XRD patterns in Fig. 5(b) and SADP in Fig. 7 indicated that phase transformations of $\mathrm{t}^{\prime}-\mathrm{ZrO}_{2}$ to $\mathrm{m}-\mathrm{ZrO} \mathrm{r}_{2}$ clearly occurred in the 7YSZ ceramic after it was subjected to VA. It was previously determined that the total volumetric change of zirconia during the transformation from tetragonal to monoclinic is about $4-5 \%$ [20], and the occurrence of such an internal volume change would induce an associated increase in residual stress, which may cause micro-cracking and damage the mechanical properties of the coating. Although yttria stabilization can minimize this phase transformation effect in most operating conditions, the extended exposure to CMAS at a high temperature caused the yttria to be diffused out of the stabilized tetragonal phase, making it prone to phase transformation $[9,16,21]$. As shown in

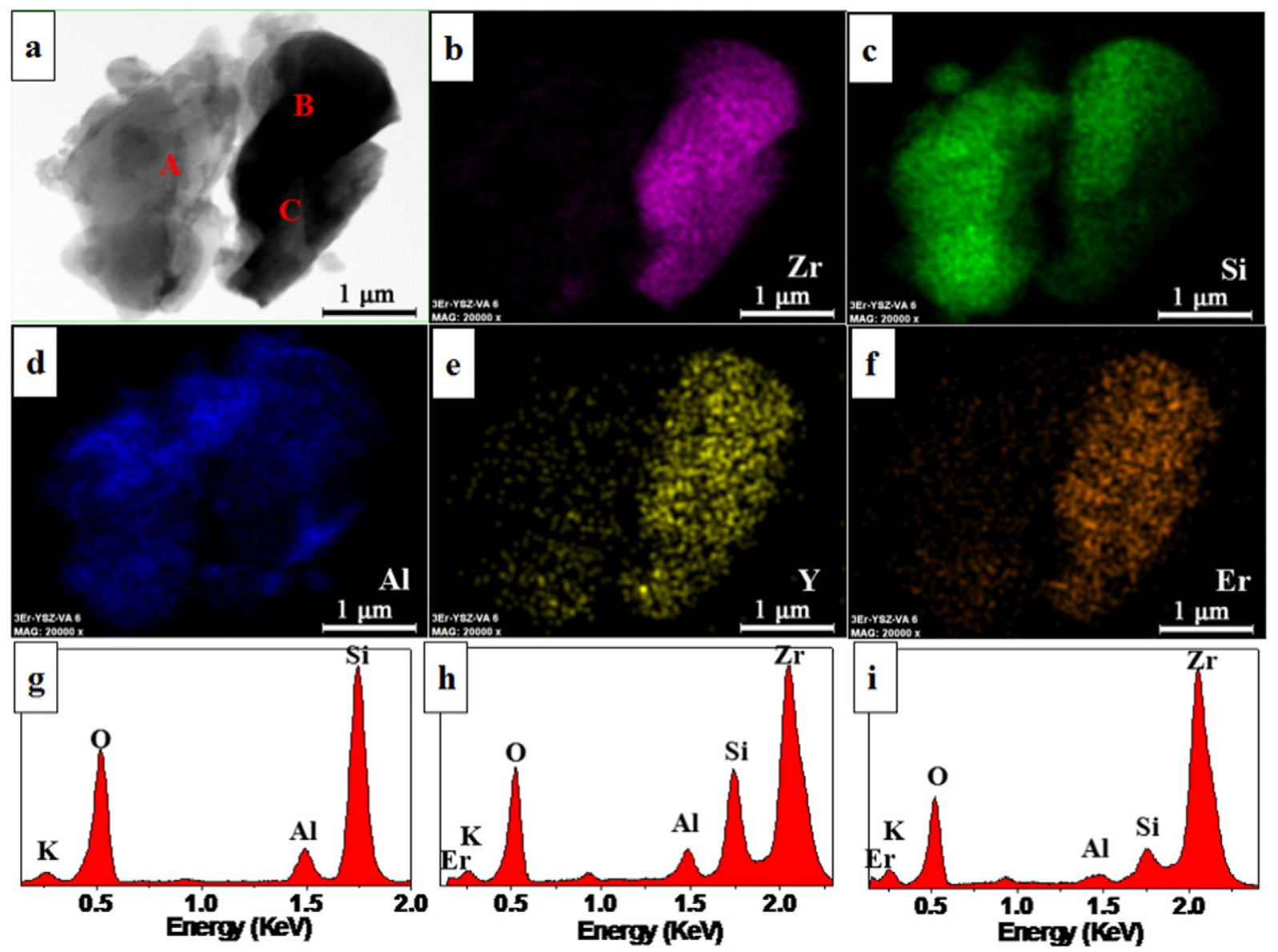

Fig. 8. (a) STEM images, (b) to (f) EDS mapping of 3Er-7YSZ/VA powders after heat treatment at $1250{ }^{\circ} \mathrm{C}$ for $5 \mathrm{~h}$ and (g) to (i) EDS spectrum in area A, B and C respectively. 
the previous study, YSZ was susceptible to CMAS at a high temperature because of the $\mathrm{Y}_{2} \mathrm{O}_{3}$ that leaked from the $\mathrm{ZrO}_{2}$ [16], which lead to a phase transformation. The present study found a similar result when using volcanic ash subjected to a high temperature of $1250{ }^{\circ} \mathrm{C}$. 7YSZ was found to have little resistance to VA penetration, which is consistent with what others have observed in CMAS [9,22]. In the present experiments, a significant phase transformation to $\mathrm{m}-\mathrm{ZrO}_{2}$ phase was not detected in the rare earth-doped samples. The addition of a small amount of rare earth oxide to YSZ resulted in a stable microstructure and $\mathrm{t}^{\prime}-\mathrm{ZrO}_{2}$ phase under VA corrosion. The combination of the STEM/ EDS and XRD results confirmed that rare earth-doped YSZ is resistant to phase transformation. Under the same experimental conditions, the extent of the phase transformation of the 7YSZ was more than rare earth-doped YSZ, revealing that the rare earth-doped YSZ suffered less damage than the 7YSZ. The rare earth-doped YSZ was found to be resistant to VA at a high temperature probably because rare earth oxidedoped YSZ is predominately tetragonal and can stabilize the tetragonal phase very well [23].

According to the $\mathrm{ZrO}_{2}-\mathrm{SiO}_{2}$ phase diagram [24], pure zircon is a stable phase. The reaction between $\mathrm{ZrO}_{2}$ and $\mathrm{SiO}_{2}$ is very slow at $1250{ }^{\circ} \mathrm{C}$ $[25,26]$. It has already been observed that cristobalite does not react with $\mathrm{ZrO}_{2}$ below a temperature of $1300{ }^{\circ} \mathrm{C}$ [27]. These results confirm the findings of Ramani et al. [27], that $\mathrm{ZrO}_{2}$ does not react with quartz. According to Itoh [28], zircon starts forming around $1300{ }^{\circ} \mathrm{C}$ and proceeds exclusively between amorphous silica and tetragonal zirconia. The results of previous experiments and studies clearly show that the investigation of the kinetics of zircon formation cannot be directly accomplished using a mixture of $\mathrm{YSZ}$ and $\mathrm{SiO}_{2}$ powders below $1300{ }^{\circ} \mathrm{C}$. However, this is contrary to the observations made in this study. The formation of zircon was observed at $1250{ }^{\circ} \mathrm{C}$ in this study. Fig. 5(b) confirms that the $\mathrm{ZrSiO}_{4}$ is the major phase in as-prepared ceramics and VA mixture powders after heat treatment. The appearance of $\mathrm{ZrSiO}_{4}$ indicates that the VA reacted with the as-prepared ceramic powder and formed a new compound. The presence of $\mathrm{ZrSiO}_{4}$ was probably due to the dissolution of $\mathrm{Y}_{2} \mathrm{O}_{3}$ from $\mathrm{YSZ}_{\text {by }}$ VA until $\mathrm{ZrSiO}_{4}$ nucleated and grew at the interface between the $\mathrm{Y}_{2} \mathrm{O}_{3}$ enriched amorphous phase and the residual $\mathrm{ZrO}_{2}[17,18]$. The presence of additional oxides may significantly accelerate the formation of $\mathrm{ZrSiO}_{4}$ [18]. These experiments have shown that rare earth oxides can considerably increase reactivity.

Both transition and melting temperatures are critical for a molten deposit attack. The solid state diffusion of the CMAS species may attack the TBCs in cases where the TBC's surface temperature is less than the CMAS melting temperature, but close enough to the transition temperature of the melt. However, when the TBC's surface temperature exceeds the melting point of the deposit, melting occurs and the TBC is infiltrated by the CMAS melt. This liquid form of CMAS attack is much faster compared to the slow, long-term solid state attack [29]. Compared with the CMAS, the melting temperature in the CMAS-7YSZ sample also shifted to lower values, with the onset depressed by $27{ }^{\circ} \mathrm{C}$ and the peak by $21{ }^{\circ} \mathrm{C}$ [29]. In all cases, it was observed that the ceramics were dissolved into molten ash and formed $\mathrm{ZrSiO}_{4}$. Zircon melts at a relatively high temperature of $2550{ }^{\circ} \mathrm{C}$ [24] and the resistance to VA depends on the amount of solute in the zirconia, which is the key to stopping the penetration. Adding more solute to zirconia drastically decreases the penetration depth of CMAS, since the additional solute enables the glass to be chemically modified faster, resulting in crystallization [30]. These crystalline phases with higher melting points can serve as a barrier to the further penetration of VA. According to the previous study, when VA reacts with alumina, forming anorthite, magnetite and spinel as reactive products, it results in a melting temperature above that of the VA [16]. In short, rare earth-doped YSZ samples were found to be effective against VA, while 7YSZ was not. The results of the solute atomic ratio and penetration depth are listed in Table 4. It is noted that more solute in the original ceramic causes a more reactive phase to precipitate, allowing less VA penetration. Penetration stops when CMAS/VA reaches regions where the local temperature is below its melting point. Infiltration is complete in isothermal exposures, but would be limited in a real operation to a depth dictated by the thermal gradient across the coating and the viscosity of the melt [9]. Current TBCs consisting of 7YSZ are ineffective in stopping VA penetration due to the low concentration of the solute. Cai et al. [31] found that $\mathrm{ZrSiO}_{4}$ forms near the top surface region of the YSZ layer and the VA penetrates the entire YSZ layer. Since the growth of $\mathrm{ZrSiO}_{4}$ is relatively slow, blocking the inter-column gaps hardly inhibits infiltration [32]. These experimental results agree with the conclusions reached in this study. In contrast to 7YSZ, rare earth-doped YSZ suffered less damage from volcanic ash. It was found in study that VA only penetrated about $100 \mu \mathrm{m}$ distance into the rare earth- doped samples from the top surface, as shown in Fig. 4. Compared with 7YSZ, rare earth-doped YSZ samples were found to have faster $\mathrm{ZrSiO}_{4}$ products, which were able to seal the inter-column gaps. Despite the fact that rare earth-doped YSZ is more porous than 7YSZ, rare earth-doped YSZ suffered less VA penetration, which suggests that microstructure porosity may a less critical role affecting VA penetration. It was demonstrated that rareearth doped YSZ might be one of the ideal TBCs ceramics to suppress damage caused by a CMAS/VA attack.

The combined data for the depth of VA penetration and the melting temperature that occurs due to different solutes and concentrations of ions in zirconia are listed in Table 4. It is apparent that in the case of rare earth-doped YSZ, adding more solute into zirconia drastically reduces the penetration depth of VA. Furthermore, a small concentration change in the lower solute regime appears to have a huge effect on reducing the depth of penetration [30]. The mitigation of molten CMAS appears to be highly dependent on solute concentration [33,34]. The mechanism of penetration will affect the nature of the thermochemical interaction between the VA and TBC materials, which will also contribute to the search for novel coating compositions.

The CMAS problem in TBCs is intrinsically thermomechanical, but thermochemical issues are relevant for formulating an effective mitigation strategy [6]. However, it should be noted that only plate and powder samples were examined in this study. The thermochemical interaction of VA and ceramics is highly complex; therefore, the results cannot be used to determine volcanic ash degradation mechanisms. Notwithstanding this limitation, the results of the study clearly indicate that adding a small amount of rare earth oxide to YSZ could effectively protect it from a VA attack.

\section{Conclusion}

Real volcanic ash, which has a composition similar to CMAS with a lower melting temperature, was utilized for this study. In the current study, 7YSZ, 0.5Gd-8YSZ and 3Er-7YSZ powders and free-standing plates were prepared. The reaction of three kinds of materials with real volcanic ash maintained at $1250^{\circ} \mathrm{C}$ in air for $5 \mathrm{~h}$ was investigated and some conclusions were drawn, as follows;

1. The VA mixed with as-prepared powders after heat treatment contains the same $\mathrm{ZrSiO}_{4}$. The presence of additional oxides may significantly accelerate the formation of $\mathrm{ZrSiO}_{4}$. Volcanic ash reacts with 7YSZ, which induces a phase transformation from $\mathrm{t}-\mathrm{ZrO}_{2}$ to $\mathrm{m}-\mathrm{ZrO}_{2}$. The mechanisms of molten VA attacks 7YSZ are somewhat similar to CMAS. However, the $\mathrm{m}-\mathrm{ZrO}_{2}$ phase was not detected in the rare earth-doped samples. 3Er-7YSZ and 0.5Gd-8YSZ suffered less damage from volcanic ash than 7YSZ.

2. After $5 \mathrm{~h}$ of heat treatment at $1250{ }^{\circ} \mathrm{C}$, the penetration depth of the 7YSZ sample was much greater than that of the rare earth-doped samples. 7YSZ was found to have a poor ability to combat volcanic ash penetration. Rare earth-doped YSZ may be used effectively to mitigate a volcanic ash attack.

3. Compared to the VA, the temperatures of the melting endotherm in the VA-7YSZ sample shifted to lower values, with the onset and peak point reduced by $14.1{ }^{\circ} \mathrm{C}$ and $22.1{ }^{\circ} \mathrm{C}$ respectively. However, 
the melting temperature increased slightly in the rare earth-doped samples.

4. The addition of solute to YSZ was found to reduce the penetration of VA. Small changes in concentration resulted in a large reduction of penetration. The 7YSZ suffered less damage from the VA attack with the increasing solute content in the materials. The rare earthdoped YSZ has the potential to provide effective protection against molten volcanic ash.

Overall, the work here has shown that YSZ ceramic resistance to CMAS and volcanic ash improves with the addition of a small amount of rare earth oxides. This study has provided new insights that can be used for the further development of VA-resistant TBCs.

\section{Acknowledgments}

This work was supported by the National Natural Science Foundation of China (Grant Nos. 51590891, 11272275, 11472237 and 11432014). The authors would like to thank Ms. Hong Gao of the National Institute for Materials Science for offering technical support on JSM-7500F FE-SEM.

\section{References}

[1] J.H. Perepezko, The hotter the engine, the better, Science 326 (2009) 1068-1069.

[2] H.B. Xu, H.B. Guo, Thermal Barrier Coatings, Elsevier, 2011

[3] N.P. Padture, M. Gell, E.H. Jordan, Thermal barrier coatings for gas-turbine engine applications, Science 296 (2002) 280-284.

[4] D.R. Clarke, M. Oechsner, N.P. Padture, Thermal-barrier coatings for more efficient gas-turbine engines, MRS Bull. 37 (2012) 891-898.

[5] A.G. Evans, D.R. Clarke, C.G. Levi, The influence of oxides on the performance of advanced gas turbines, J. Eur. Ceram. Soc. 28 (2008) 1405-1419.

[6] C.G. Levi, J.W. Hutchinson, M.-H. Vidal-Setif, C.A. Johnson, Environmental degradation of thermal-barrier coatings by molten deposits, MRS Bull. 37 (2012) 932-941.

[7] M.P. Borom, C.A. Johnson, L.A. Peluso, Role of environmental deposits and operating surface temperature in spallation of air plasma sprayed thermal barrier coatings, Surf. Coat. Technol. 86-87 (1996) 116-126.

[8] F.H. Stott, D.J. De Wet, R. Taylor, Degradation of thermal barrier coatings at very high temperatures, MRS Bull. 19 (1994) 46-49.

[9] S. Krämer, J. Yang, C.G. Levi, C.A. Johnson, Thermochemical interaction of therma barrier coatings with molten $\mathrm{CaO}-\mathrm{MgO}-\mathrm{Al}_{2} \mathrm{O}_{3}-\mathrm{SiO}_{2}$ (CMAS) deposits, J. Am. Ceram. Soc. 89 (2006) 3167-3175.

[10] O. Trunova, T. Beck, R. Herzog, R.W. Steinbrech, L. Singheiser, Damage mechanisms and lifetime behavior of plasma sprayed thermal barrier coating systems for gas turbines-part I: experiments, Surf. Coat. Technol. 202 (2008) 5027-5032.

[11] R. Darolia, Thermal barrier coating technology: critical review, progress update, remaining challenges and prospects, Int. Mater. Rev. 58 (2013) 315-348.

[12] H.B. Zhao, C.G. Levi, H.N. Wadley, Molten silicate interactions with thermal barrier coatings, Surf. Coat. Technol. 251 (2014) 74-86.

[13] W. Pan, S.R. Phillpot, C.L. Wan, A. Chernatynskly, Z.X. Qu, Low thermal conductivity oxides, MRS Bull. 37 (2012) 917-922.
[14] R.G. Wellman, J.R. Nicholls, Erosion, corrosion and erosion-corrosion of EB PVD thermal barrier coatings, Tribol. Int. 41 (2008) 657-662.

[15] X.Q. Cao, R. Vassen, D. Stoever, Ceramic materials for thermal barrier coatings, J. Eur. Ceram. Soc. 24 (2004) 1-10.

[16] K.I. Lee, L.T. Wu, R.T. Wu, P. Xiao, Mechanisms and mitigation of volcanic ash attack on yttria stablized zirconia thermal barrier coatings, Surf. Coat. Technol. 260 (2014) 68-72.

[17] W.R. Chen, L.R. Zhao, Review-volcanic ash and its influence on aircraft engine components, Procedia Engineering 99 (2015) 795-803.

[18] P. Mechnich, W. Braue, U. Schulz, High-temperature corrosion of EB-PVD yttria partially stabilized zirconia thermal barrier coatings with an artificial volcanic ash overlay, J. Am. Ceram. Soc. 94 (2011) 925-931.

[19] H.G. Scott, Phase relationships in the zirconia-yttria system, J. Mater. Sci. 10 (1975) 1527-1535.

[20] R.A. Cutler, J.R. Reynolds, A. Jones, Sintering and characterization of polycrystalline monoclinic, tetragonal, and cubic zirconia, J. Am. Ceram. Soc. 75 (1992) 2173-2183.

[21] R.K. Amanda, H.F. Garces, G. Dwivedi, A.L. Ortiz, S. Sampath, N.P. Padture, Calciamagnesia-alumino-silicate (CMAS)-induced degradation and failure of air plasma sprayed yttria-stabilized zirconia thermal barrier coatings, Acta Mater. 105 (2016) 355-366.

[22] A. Aygun, A.L. Vasiliev, N.P. Padture, X. Ma, Novel thermal barrier coatings that are resistant to high-temperature attack by glassy deposits, Acta Mater. 55 (2007) 6734-6745.

[23] D.M. Zhu, Y.L. Chen, R.A. Mille, Defect clustering and nano-phase structure characterization of multi-component rare earth oxide doped zirconia-yttria thermal barrier coatings, Ceram. Eng. Sci. Proc. 24 (2003) 525-534.

[24] B.C. William, R.F. Wilfrid, Zircon stability and the $\mathrm{ZrO}_{2}-\mathrm{SiO}_{2}$ phase diagram, Am. Mineral. 52 (1967) 880-885.

[25] Y. Kanno, Discussion on the double oxides formation in the systems of $\mathrm{ZrO}_{2}-\mathrm{SiO}_{2}$, $\mathrm{ZrO}_{2}-\mathrm{TiO}_{2}$ and $\mathrm{TiO}_{2}-\mathrm{SiO}_{2}$, J. Mater. Sci. Lett. 9 (1990) 765-767.

[26] D.R. Spearing, J.Y. Huang, Zircon synthesis via sintering of milled $\mathrm{SiO}_{2}$ and $\mathrm{ZrO}_{2}$, J. Am. Ceram. Soc. 81 (1998) 1964-1966.

[27] S.V. Ramani, E.C. Subbarao, K.K. Gokhale, Kinetics of zircon synthesis, J. Am. Ceram. Soc. 52 (1969) 619-623.

[28] T. Itoh, Formation of polycrystalline zircon $\left(\mathrm{ZrSiO}_{4}\right)$ from amorphous silica and amorphous zirconia, J. Cryst. Growth 125 (1992) 223-228.

[29] E.M. Zaleski, C. Ensslen, C.G. Levi, D. Butt, Melting and crystallization of silicate systems relevant to thermal barrier coating damage, J. Am. Ceram. Soc. 98 (2015) 1642-1649.

[30] J.M. Drexler, A.L. Ortiz, N.P. Padture, Composition effects of thermal barrier coating ceramics on their interaction with molten $\mathrm{Ca}-\mathrm{Mg}$-Al-silicate (CMAS) glass, Acta Mater. 60 (2012) 5437-5447.

[31] C.Y. Cai, S. Chang Y.C. Zhou, L Yang G.W. Zhou, Y.G. Wang Microstructure characteristics of EB-PVD YSZ thermal barrier coatings corroded by molten volcanic ash, Surf. Coat. Technol. 286 (2016) 49-56.

[32] R.W. Jackson, E.M. Zalesk, D.L. Poerschke, B.T. Hazel, M.R. Begley, C.G. Levi, Interaction of molten silicates with thermal barrier coatings under temperature gradients, Acta Mater. 89 (2015) 396-407.

[33] J.M. Drexler, A.D. Gledhill, K. Shinoda, A.L. Vasiliev, K.M. Reddy, S. Sampath, N.P. Padture, Jet engine coatings for resisting volcanic ash damage, Adv. Mater. 23 (2011) 2419-2424.

[34] A.D. Gledhill, K.M. Reddy, J.M. Drexler, K. Shinoda, S. Sampath, N.P. Padture, Mitigation of damage from molten fly ash to air-plasma-sprayed thermal barrier coatings, Mater. Sci. Eng. A 528 (2011) 7214-7221. 